\title{
La visita de Santiago de Liniers a los pueblos de San Cosme, Santiago, Santa Rosa, San Ignacio Guazú y Santa María de Fe
}

Silvana M. Lovay

El 6 de enero de 1804 el gobernador interino de las misiones, el capitán de navío Santiago de Liniers le dirigió al virrey un informe sobre el estado de antiguas reducciones jesuíticas ubicadas en el departamento Santiago.

Como sabemos, y de eso bien se ocupó Julio César González en $1946^{1}$, quien tendría un promisorio aunque trágico futuro en el Río de la Plata, fue gobernador interino del territorio de las antiguas reducciones jesuíticas del Paraguay. Luego de la expulsión de los ignacianos, el gobernador de Buenos Aires Francisco de Paula Bucarelli y Ursua (17661770) dictó las Ordenanzas de 1768 en que dividió el territorio de las reducciones en dos gobernaciones $^{2}$. La Real Ordenanza de Intendentes aplicada en 1784 fracturó la unidad al crearse las intendencias de Buenos Aires y Paraguay que se repartirían las jurisdicciones de las misiones, lo cual generó un descontrol administrativo que repercutió en el abandono de las estancias, cuyas tierras fueron tomadas por los portugueses levantados en guerra en 1801. Lo cierto es que el departamento San Miguel se perdió, aunque el resto se unificó y continuó llamando gobernación de los “Treinta Pueblos de las Misiones Guaraníes”, conformada en tiempos de Liniers por cuatro departamentos: Candelaria, Santiago, Concepción y Yapeyú con 32.000 vasallos del rey.

Efectivamente el mismo Liniers le solicitó al virrey Joaquín del Pino que lo nombrara en aquel cargo en reemplazo del coronel Joaquín de Soria. Así lo hizo formalmente y a su favor el 5 de noviembre de $1802^{3}$, prestando el juramento de forma ante la Real Audiencia de Buenos Aires. Su principal problema a resolver era la defensa del territorio, siempre acechado por los lusitanos, quienes -como dijimos- el año anterior habían tomado los siete pueblos de la Banda Oriental y hacían periódicas incursiones a su territorio.

Liniers llegó a Candelaria el 6 de marzo del año siguiente fijando allí su residencia y siendo testigo del abandono en que se encontraban las misiones jesuíticas por la desidia del

\footnotetext{
${ }^{1}$ González, Julio César (1946), Don Santiago de Liniers gobernador interino de los treinta pueblos de las misiones guaraníes y tapes 1803-1804, Buenos Aires: Facultad de Filosofía y Letras - UBA.

${ }^{2}$ Nombró como gobernadores interinos a Francisco Bruno Zabala para que administre los diez pueblos del Uruguay y a Juan Francisco de la Riva Herrera los veinte pueblos restantes. El primero pasó luego a ser gobernador interino de todos los pueblos, con tres departamentos a cargo de tenientes de dragones del regimiento de Buenos Aires, con sedes en Yapeyú, San Miguel y Santiago.

${ }^{3}$ AGN. Virreinato. Libro 32, folio 249. Titulo: Gobernador interino de los treinta Pueblos de Misiones Guaraníes y Tapes, expedida el 5 de noviembre de 1802.
} 
mismo virrey, sobre todo en lo que respecta a la defensa militar. Liniers trabajó con todo afán al respecto, aunque solitario y sin ayuda, con un reducido numero de soldados con armamento casi inútil. Pero no era todo, las continuas enfermedades y escasa asistencia hospitalaria le hicieron reclamar el nombramiento de un médico por departamento. En lo económico intenta suprimir las concesiones dadas a particulares (yerbateros) para la explotación de la yerba pues perjudicaban a la comunidad a la que recomendaba fueran repartidas tierras para la producción agropecuaria, como lo había hecho en parte el virrey marqués de Avilés.

Todas sus ideas fueron expresadas al virrey del Pino en un sinnúmero de $\operatorname{cartas}^{4}$ y al mismo monarca en un extensa Memoria ${ }^{5}$.

El deber de visitar los pueblos ya lo había impartido el gobernador Bucarelli a los efectos de empadronamiento de los pueblos. Pero el virrey marqués de Avilés se detuvo en redactar 15 detallados puntos dedicados a qué deberían especificar los gobernadores en sus obligatorias visitas $^{6}$. De tal forma que el gobernador debía dar cuenta de la labor de los administradores de los pueblos, inspeccionando libros matrices y diarios, movimiento de bienes de la comunidad, trabajadores empleados, convenios comerciales celebrados, entrega de vestuario, asistencia médica, relevamiento de las existencias en almacenes y recuento de ganados. Finalmente el gobernador debía recorrer el pueblo para observar el estado de las casas de comunidad y particulares.

Pues Liniers dio cumplimiento a este acto de gobierno con suma severidad en tanto pretendía reemplazar administradores corruptos de los que tenía perfecto conocimiento. Pero diversos factores hicieron demorar la visita que solo se concretó recién en el mes de diciembre de 1803 al departamento Santiago, donde Liniers también había sido nombrado teniente de gobernador. El departamento constaba de cinco pueblos: San Cosme, Santiago, Santa Rosa, San Ignacio Guazú y Santa María de Fe. Una vez finalizada la visita el gobernador interino elevó el informe al virrey ${ }^{7}$ y es el que pasamos a transcribir.

\section{Exmo. Señor}

Encargado por V.e. del departamento de Santiago por su Providencia del 30 de setiembre, determiné desde luego pasar á visitarlo, lo que los malos tiempos y continuas lluvias que harian intransitable los caminos y arroyos me lo embarazaron hasta principio del próximo pdo. que lo verifique pudiendo asegurar a V.e. que no deja nada que desear el

\footnotetext{
${ }^{4}$ AGN, Sala IX, 18-8-8. División Colonia. Gobierno. Copiador de correspondencia del Gobernador de las Misiones don Santiago de Liniers al Virrey del Río de la Plata 1803-1804.

${ }^{5}$ Copia del original firmada por Liniers el 6 de julio de 1804 en Museo Mitre, sección manuscritos Arm. B, C. 29, P. $1 \mathrm{~N}^{\mathrm{o}}$ de orden 18. Transcripta por Paul Groussac, revista La Biblioteca, año 1, T.II, Buenos Aires, 1897, pp. 466-473.

${ }^{6}$ AGN-BN, Legajo 293, doc. 4593, Diligencias que debo practicar en cada pueblo de indios en razón de visita...1799

${ }^{7}$ AGN, Sala IX, 18-3-3. División Colonia, Sección Gobierno. Misiones 1803-1804.
} 
buen orden la coordinación, y fomentos de los ramos de Industria y Agricultura, establecidos, por el zelo, actividad, y inteligencia del Teniente de él Dn. Pedro Durán ${ }^{8}$.

El primero Pueblo en que entre fué el de San Cosme, situado a media milla del Paraná donde forma un buen Puerto dho. Rio antes de encuentrar el Salto grande. Este pueblo tiene su Colegio en buen estado, ygualm ${ }^{\text {te }}$ que su Yglesia, aunque Provisional, sus Trapiches nuevos, este año a Cosechado Ciento y Ocho Arrovas de Azucar, y Doscientos Azumbres de Miel. Ciento y uno Fanegas de Trigo, tiene de repuesto Quatrocientos Arr ${ }^{\mathrm{s}}$ de Algodón, y Quatro pzas. de Lienzo en sus Almacenes; las havitaciones de los Naturales en numero de ellas de mil Almas, forman una doble quadras de Casas alrededor de la Plaza, están separadas por una Calle // espaciosa, las Paredes en mui buen estado, pero los tejados necesitan de lgunas reparaciones. El Adm ${ }^{\text {or }}$. Dn. Sancho Escudero, es hombre honrrado, y activo, pero demasiado inclinado al Mecanismo Económico que además de haserle despreciar de los Naturales le atrahe el odio de los demás empleado. Tiene en sus estancias sobre Doze mil cavezas de todo Ganado, de ese Pueblo pasé a el de Santiago, este Pueblo capital del Departamento no es mas que una sombra de lo que fue antiguam ${ }^{\text {te }}$. y ultimam ${ }^{\text {te }}$. ha padecido infinito con la Libertad parcial de sus Naturales por cuya causa a perdido varios Algodonales sin embargo recoje años comunes sobre Ochocientos á mil arrovas. Si Yglesia de una sola nabe no es Correspondiente a la entidad del Pueblo que de mil trec ${ }^{\text {tas }}$. Almas, pero que es suceptible de mucho aumento tiene Yervales artificiales $\mathrm{q}^{\mathrm{e}}$ pueden dar sobre mil arr ${ }^{\mathrm{s}}$. de Yerba al año Cosecha algun Azucar, pero sus terreros no son propios $\mathrm{p}^{\mathrm{a}}$. esta cultura. El $\mathrm{Adm}^{\text {or }} \mathrm{d}^{\mathrm{n}}$. Pedro Ribera parece tener bastante actividad, y se halla reedificando las havitaciones de los naturales deterioradas por el abandono de los Indios libres, quienes $\mathrm{p}^{\mathrm{a}}$. formar sus Chacaras á largas distancias del Pueblo las han abandonado llevandose Puertas, y Ventanas sobre cuio esceso he dado Providencia, obligandolos a que precisamente mantingan sus Casas en buen estado en el Pu. y se vennan mas al Pueblo, para no carecer del culto y instrucciones desus Pastores. Este Pueblo tiene en sus // estancias sobre sinquenta y cinco mil quinientos diez y nueve cabezas delganado de toda clase, y aunque del bacuno mas de la mitad esta alsado seva rediriendo á rodeo.

Este rápido informe no me permite extenderme sobre los perjuicios de esta mal concebida, y peor executada Libertad todos los Yndios libres estan en el entender que ser libre, es ser esento de toda pratica de Religion, y gozar de una total independencia de todas Leyes, yo he procurado disuadirle de esta fatal preocupación, castigando con mas severida las faltas de los libres que la de los de Comunidad, mucho de ellos han solicitado volver a ella, pero otros despues de haver consumido el poco Ganado que tenían, no viven mas que de Rapiña.

Del Pueblo de Santiago pase a el de $S^{\text {ta }}$. Rosa, hermoso Pueblo de Mil doscientas Almas con Trescientos Yndios de Tareas, recogio solo este año Sesenta fanegas de Trigo, Ciento y Ocho Arrs. de Azucar de qualidad inferior por algun descuido en el Beneficio, y Cinco sinq ${ }^{\text {ta }}$. Arrovas de Miel, tiene Quarenta mil plantas de Tavaco , su Yglesia es somptuosa de tres naves con su media naranja, y es sin contradicción la mas rica en Alajas de plata, y Oro, siendo digno de atención un Caliz de este metal travajado del mejor gusto,

\footnotetext{
${ }^{8}$ Tanto don Pedro Antonio Durán como don Francisco Bermúdez, ambos tenientes de gobernador de los pueblos de Santiago y Yapeyú fueron reemplazados por disposición del virrey del 30 de setiembre de 1803, por Santiago Liniers y don José de Lariz, respectivamente. Las causas se originaron en su mal desempeño frente a la ocupación portuguesa de la Banda Oriental (González, 1946:156).
} 
los Ornamentos son ygualmente numerosos Ricos, y tambien conservados $\mathrm{q}^{\mathrm{e}}$. parece se acaban de hacer tiene las mejores pinturas que existen en la Provincia. El Administ ${ }^{\mathrm{or}}$. $/ / \mathrm{D}^{\mathrm{n}}$. Tomas Esperati es bastante activo, pero en el poco tiempo que se halla en la $\mathrm{Adm}^{\mathrm{on}}$. No ha podido dar pruevas concluientes desu suficiencia. Tiene este Pueblo Veinte y dos mil Seiscientas treinta y uno cabezas de todo ganado.

De Santa Rosa pasé a $S^{\mathrm{n}}$. Ygnacio Guazu, este Pueblo consta solo de Seiscientos sesenta y siete Almas. Sus Cosechas principales son el Algodón del que años malos recoge a lo menos Trescientas Arrs ${ }^{\mathrm{s}}$ aunque suelen faltar algunas veces por los muchos riesgos que corre esta planta, tambien es propio $\mathrm{p}^{\mathrm{a}}$. Trigo, y Chacarerio, este año la faltó la cosecha del Trigo no habiendo recojido mas que Veinte y dos Fanegas, este Pueblo que fue uno de los mas Poblados del Departamento sufrió una inmensa baja de una epidemia de Viruela el año de 1797, que lo asolo, sus Tierras no son propias para la caña, no recojiendo mas $\mathrm{q}^{\mathrm{e}}$. lo necesario $\mathrm{p}^{\mathrm{a}}$. el gasto de Azucar y Miel del Pueblo, pero es regular para el Tavaco, tiene Yervales artificiales, $q^{\mathrm{e}}$. le proveen ygualm ${ }^{\text {te }}$. para su consumo. Acaba de reedificar su Yglesia de tres naves, con un hermosísimo atrio con cinco gradas de losas todo el tejado se halla asegurado con cal, y sentado sobre bosta, este sumptuoso edificio hace un contraste orroroso con la Casa de Cavildo, y todas las habitaciones de los Naturales $\mathrm{q}^{\mathrm{e}}$. caen en ruina, pero de cuia reedificación se esta tratando, haviendo ya para el efecto buen acopio de Maderas, y de materiales tiene Quince mil y Veinte Cavezas de todo Ganado, su Adm ${ }^{\text {or }}$. Me parece de regular desempeño ${ }^{9}$.

De San Ygnacio Guasu pasé a S ${ }^{\text {ta }}$. Maria de Fee, Población de Mildoscientos treinta y cinco Almas de Comunidad, mas Ciento y veinte libres, su Yglesia de hermosa Arquitectura esta amenazando ruina, pero seva a reedificar estando ya acopiados los materiales, y bajo la dirección del primoroso Maestro d ${ }^{\mathrm{n}}$. Tomas Marmol, quien reedifico la de $\mathrm{S}^{\mathrm{n}}$. Ygnacio Guasu. Los Terrenos de este Pueblo son propios oara el Azucar, y Alg . este año de esacases ha recojido del primer renglon Ochenta arrovas, y Doscientos quarenta y nueve asumbres de Miel, y del segundo Quatrocientos Ochenta arr ${ }^{\mathrm{s}}$. siendo sus Cosechas años regulares del doble tambien es propio para el chacarerio dando con abundancia toda clase de Miniestras recoje desus Yervales artificiales Quin ${ }^{\text {tas }}$. Arrovas de Yerva, encuentren en el Almacen sobre cien Armas de fuego en mal estado, pero suceptible de mui buena Composicion, las Casas de los naturales en mal estado, el Cavildo en el suelo; tiene Diez Telares ocupados, un Maestro Español era pagado por el $\mathrm{Pu}^{\circ}$. para enseñar la Fabricacion de Sombrero Ordinario, tiene en Estancia sobre veinte y quatro mil ochocientos y quarenta y seis Cavezas de todo Ganados. El Administrador me debe el concepto de hombre honrado e inteligente, y sumamente activo a pesar dela salud mas achacosa.

Nuestro Señor

Guarde a V.d. muchos años. Candelaria 6 de enero de 1804 Ex $^{\text {mo }}$ Señor Santiago Liniers

\footnotetext{
${ }^{9}$ Lo era Manuel Trinidad Gómez quien estuvo a cargo de las obras de la iglesia proyectada por Tomás Mármol (González, 1946: 106), que como leeremos más adelante también reconstruyó la iglesia de Santa María de Fe. Aparentemente nacido en Buenos Aires, Mármol fue comisionado para realizar las obras del Fuerte del Río Apa, pero se excusó por estar enfermo y falleció al poco tiempo (Gutiérrez, 2006: 146).
} 


\section{Bibliografía}

González, Julio César (1946), Don Santiago de Liniers gobernador interino de los treinta pueblos de las misiones guaraníes y tapes 1803-1804, Buenos Aires: Facultad de Filosofía y Letras - UBA.

Gutiérrez, Ramón et.al. (2006), Arquitectura Hispanoamericana en el Río de la Plata. Diccionario biográfico de sus protagonistas. 1527-1825, Buenos Aires: CEDODAL. 